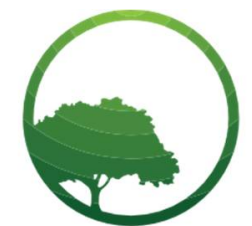

Business \& Social Science IJRBS

\section{Research in Business \\ and Social Science}

IJRBS Vol 5 No 6, 2016 ISSN: 2147-4478

Contents available at www.ssbfnet.com/ojs

https://doi.org/10.20525/ijrbs.v5i6.623

\title{
Providing an Efficient Organization Structure and Company Culture by Embedding Group Dynamic Consciousness
}

\author{
Mehmet Saim AŞÇı \\ Lecturer, Istanbul Medipol University, Istanbul, Turkey
}

\begin{abstract}
In this study, accepting the value and importance of the official organization, it is aimed to assess the idea that unofficial organization is real and important at least the official organization. Becouse at the same time organizations are feelings system, it is beneficial to determine the role of the human in the organization and to regulate the organizationto this fact. It has been also demonstrated that effective groupt interactions affected behaviours and emotions of group members in an efficient organization.
\end{abstract}

Key words: Official (Formal) Organizations, Unofficial (Informal) Organizations, Group Dynamics, Organizational Clicks, Organizational Groups

JEL classification: M12, M14

\section{Introduction}

As being a psychosocial creature, the human composing the organization has series of behavioral talents like feeling, idea, desire, ambition, hope and fear. Humans, besides their technical abilities, bring their hopes and concerns, their life philosophy, all exclusive behaviors with them to organizations where they belive they realize their porsonel hopes and desires and establish cooperation. As a result, established organization has social, human structural property including different personal ideas and behaviors. It was understood that, humans in the organization do not always behave according to rules, which were set by management, and the economical human logic.

Human behave in accordance with their emotions and feeling. Because organizations can not satisfy all needs of humans by assigning formal tasks and physical facilities. As a result of these complex reasons generally the members of the organizations, which are established to perform certain official tasks, 
establish unofficial organizations by developing relations among themselves in order to satisfy their personal needs and feelings.

No matter how important external moulds of a company (whether its institution structure or production technology) is deemed to be, unless they are merged with the alive active factors (human factor and mentality), they won't make much sense. What happens at the profound can be considered to be more important than external indicators with this point of view (Ülgener, 1981).

If countries who embrace same production operations and similar law techniques continue to have different results when it comes to financial living, where else can we search the cause of this other than mentality and attitude differences?

This study begins with theoretical framework for efficient organization by creating and active organization structure on group. Then, it concludes with suggestions by assessing the effects of groups on individuals in an efficient organization.

\section{Conceptual Framework for Efficient Organization: Creating an Active Organization Structure on a Group}

\section{Humans and Organizations}

Organization, as one of the functions of management exits in every place where multiple humans make a bid for a mutual purpose. Preparing an end of year ball, making a wedding ceremony, going for a summer vacation and many other similar things require organization. Organization has human requirements lying under its foundations. Fulfilling the requirements that arise with coexistence as a society requires organizations which are social units and this makes examination of organizations inevitable (Özalp, 1986).

Human, as a humane factor creating organizations, because it's a psychosocial entity, possesses certain behavioural talents such as feelings, thoughts, desire, ambition, hope and fear. Individuals earn these traits from birth, experience, from the environment they grow up or by being affected by other people. The also bring all their distinctive behaviours, life philosophies, their hopes and worries with their feelings and emotions aside from their technical abilities to organizations that they created if they believe they can make their desires happen and were able to create some sort of collaboration. By doing so, an organization carries social and a humane structure while involving different personal thoughts and behaviours.

In this sense, an organization is not only a collective operation centre by using various techniques to enrich economical lives, but also is a social structure that inhabits various properties of the human groups that form it and it's the result of a humane coincidence that creates these relations (Ülgen, 1990).

\section{Official Organizations-Unofficial Organizations:}

Formal aspect of organizations has always attracted the attention of many researchers. In many works, whether it's military or political, formal aspects and properties of organizations have been mentioned.

If this literature is examined, four factors that carry great importance about defining official organizations can be fixated (Dereli, 1976).

We can sort them like this;

1. A System Made out of Coordinated Activities

Every organization is made of certain parts and relationships. Organizations part consists of certain functions and performed activities. Official organization refers to the organization of these activities in reasonable relationships.

2. Particular Group of Humans

There is a demand of certain people to oversee activities about the organizations.

3. Cooperation to Reach a Certain Goal 
Cooperation is completely about human behaviour and is always directed into a purpose. Therefore, an organization needs to have aims and goals to reach for it to have a meaning for people that are about to do certain activities.

4. Authority and Leadership

Organizations are founded with a hierarchy between superior-inferior relationship tracings. As a natural result to this, authority is a universal factor that exists in all official organizations. Aside from that, leadership is a personal trait that belongs to management and it motivates employees towards a certain goal.

By merging these factors, we can define official organization this way. Official organization is a system of coordinated activities done by a group of individuals serving a common goal while cooperating with authority and leadership.

After studies that focused on emotions of humans and working groups; little groups, clicks and emotions that are ignored on rational models are mentioned heavily. This approach is named "Humane Communications" and in this approach, official organization and its relations with its environment are ignored. Official organization is viewed as a structure that determines financial structure on paper and social organization in business has become a main topic of research. An employee is no longer considered as an independent individual, it is seen as a member of a group and its behaviour is determined by group norms and values extensively.

It was realized that the employee does not always follow the rules that are defined by the management under the logic of "Financial human", in other words employees act rationally while being restricted by their emotions (Eren, 1984).

Because of these reasons which appear to be complicated, generally to achieve an official goal, to be able to satisfy their individual needs or feelings, members of an organization create unofficial organizations by developing certain relations amongst each other.

\section{Groups in Achieving Commong Goals in Organizations}

The word "group" that we use in our daily lives determines being plural. We use the term "group" to define two or more individuals who are in relations with each other to achieve a common goal.

In social psychology and sociology, concept of group is defined in multiple ways. According to these definitions, in order for a crowd to be an actual group, there are some conditions like common norms, common purposes and feeling themselves as a group.

Individuals are factors that have constructive and connective properties with physical and social order. Similar to individuals, they struggle to keep living and protect their existence. They take precautions against certain dangers that every living inevitable suffers from, such as division, disintegration and they also put effort to grow and evolve with evaluating environmental opportunities with their own means.

However, similar to all living creatures and individuals, when they face dangers or challenges they can't overcome or if they believe they can't solve their problems with their own means, discontent, discomfort and lack of balance appears within the group.

\section{Formal Groups}

Formal groups are formed to make openly appointed tasks real by overseeing specific tasks.

These groups are usually formed deliberately by a position beyond the group to carry out certain functions. These groups are structured and "organized" between members to oversee distribution of roles and determining the work explicitly (Kağıtçıbaşı and Cemalciler, 2015).

These types of groups show mainly these properties:

- Role, authorization and responsibilities of every member is determined and explained. 
- Relations between the members are arranged.

- They have a strong and well planned structure but also proportionally inflexible due to the importance they give to figures.

- Membership is earned consciously at a specific time and usually openly.

\section{Informal Groups}

Members who are formed to oversee some specific tasks formally generally make these informal groups to satisfy their own personal needs and feelings by developing certain relations amongst each other. If we call the group which depends on the purpose and the structure of the organization formal group, we can define informal groups as less organized with enclosed behaviours compared to formal groups (Eren, 1984).

Organizations that ensure often and elongated relations between humans for the sake of duty cause informal groups to arise. The reason of this is because; organizations can't provide all needs of humans with its formal tasks and financial possibilities.

One of the most common informal groupings in organizations is horizontal clicks.

The reason such grouping occurs is the frequent communication and relations between each other, amongst people who has the same title, wage, authorization and responsibility levels, shortly equals more or less in the same hierarchical order. As common properties and similarities get more and more, common profits, mutual benefits, cooperation and providing service possibilities also increase. In such states, horizontal clicks arise as seen at the figure below.

Another type of grouping is also known as vertical clicking which is founded between individuals in different positions in a hierarchy. Individuals who have chance of communicating often because they work in same department, due to having similar tasks and culture from the same department, they create an understanding and they cooperate to solve rising problems by vertical clicking.

Being the member of a specific organization department or side is the most important factor that separates them from other departments and this forms the foundation of vertical clicking.

Table 1: Horizontal Clicks in Organizations

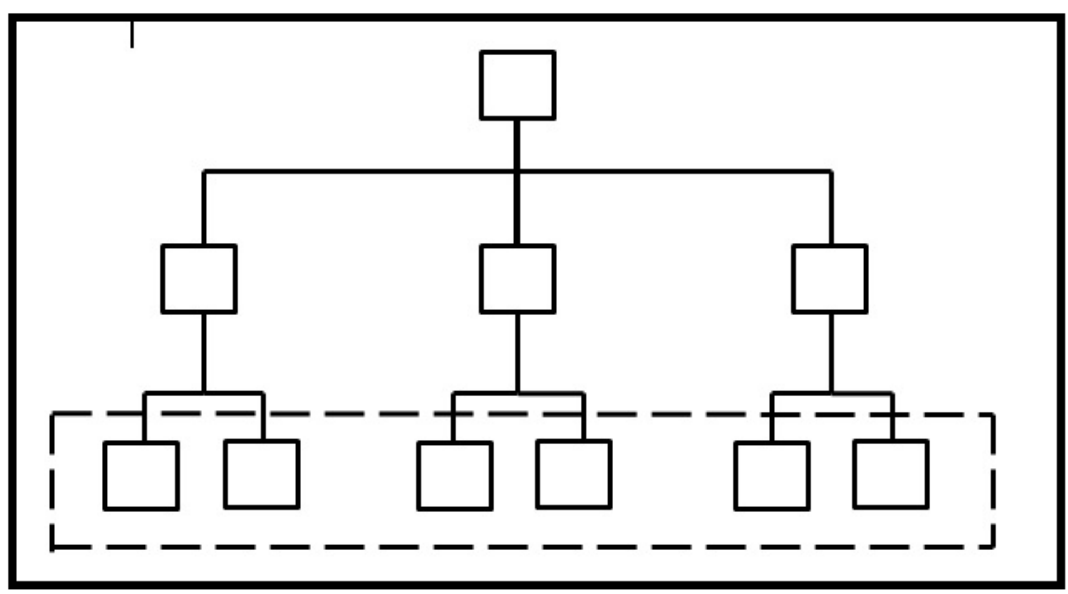

Here, organizations members are in a superior-inferior relationship and higher position requires the efforts of the lower position to oversee the tasks and goals given to it.

Communication and connections with respect to interests increase relations and make it easier to form horizontal clicks. 
Table 2: Vertical Clicks in Organizations

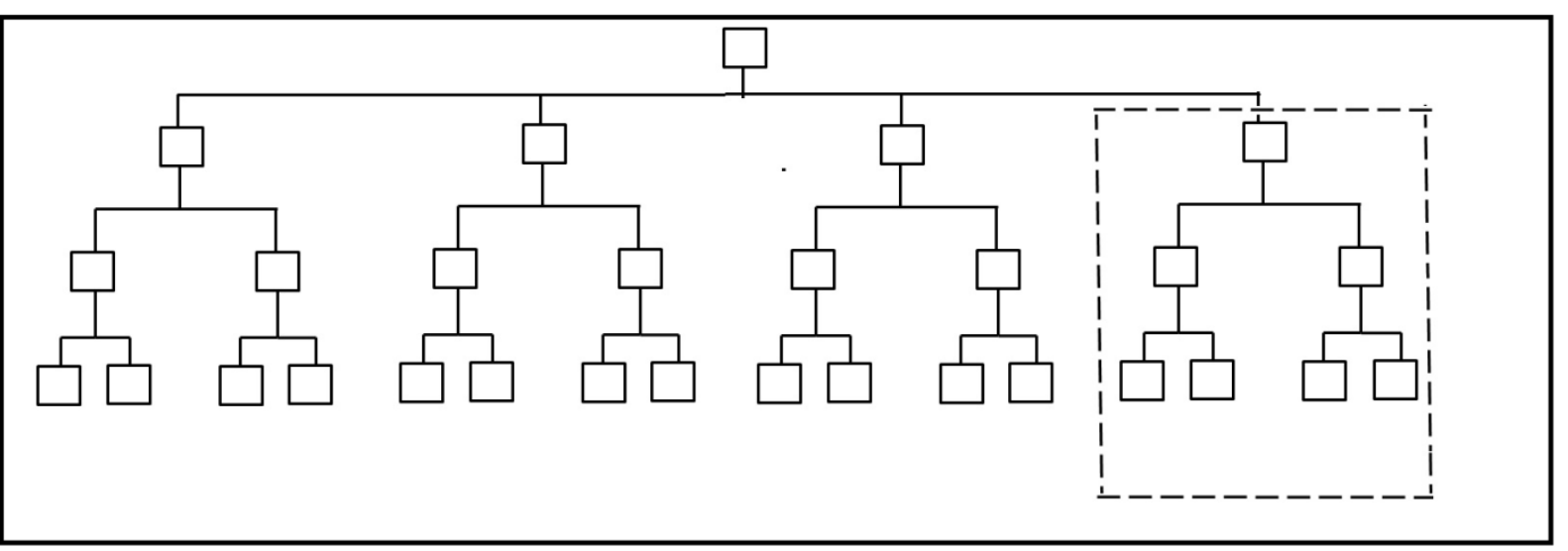

Third informal grouping is cross clicks. These groups are clicks that are formed by different hierarchic positions and made by individuals who work in different places.

Members of these groups have come together due to their certain common properties.

For example; citizenship, having a similar culture, graduating from the same education or school, belonging to the same association, having similar desires (such as gaming or entertainment) and having similar feelings are some of the reasons they feel the need to get close to each other. By doing so, between members, mutual understanding and protecting certain interests come into question, and certain specific needs that are often ignored by formal groups will also be met.

Biggest benefit of informal cross clicking is, by overcoming formal communication channels that are formed by hierarchic levels, tasks can be concluded quickly in short time with non-bureaucratic channels. However certain clicking can cause favouritism, discontent and conflicts can arise because of this reason.

Table 3: Cross Clicks in Organizations

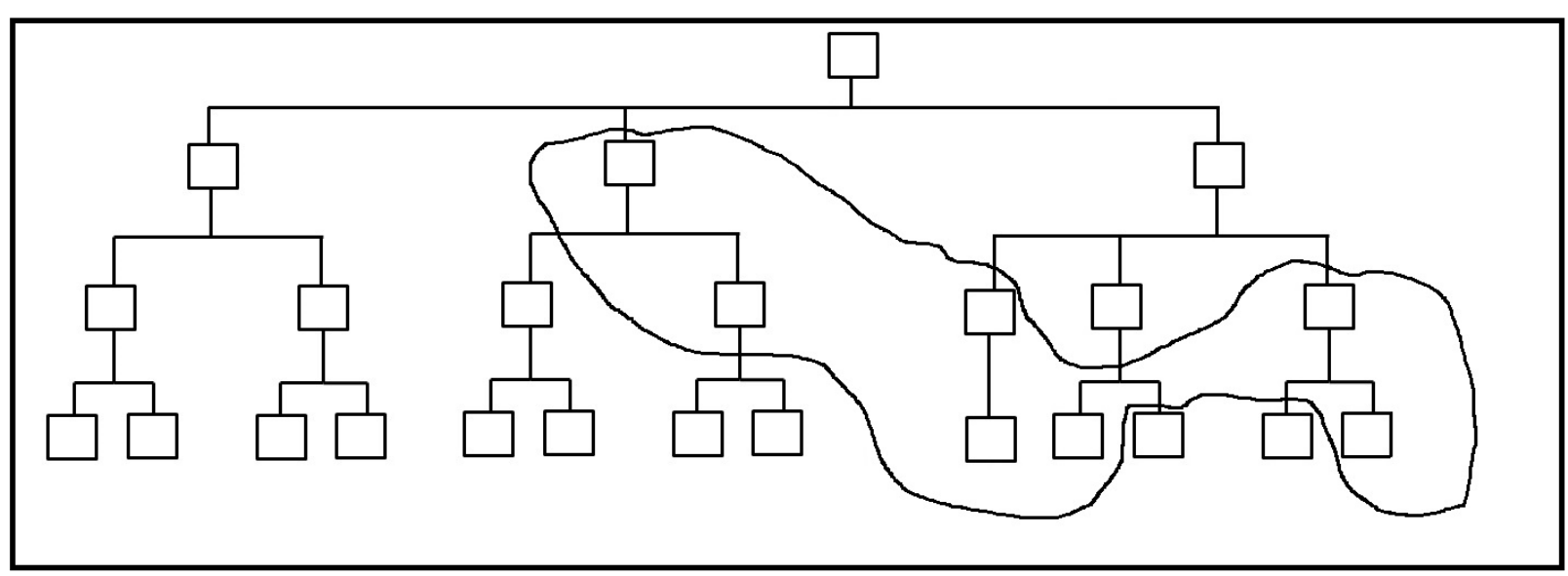

Peer-reviewed Academic Journal published by SSBFNET with respect to copyright holders. 


\section{Group Dynamics}

Little groups existed ever since the first human created families and these little groups have been generalized and philosophized throughout the ancient history.

For example, Aristophanes who lived in BC 400 in Lysistrata prepared a drama that involves unity and disorganization within a group. With this, humans could only start to examine working processes of groups scientifically in recent past (Kağıtçıbaşı, 2015).

The least required condition for a crowd to become a group is interaction and according to this, group can be defined as multiple humans interacting with each other. By doing so, every member of the group is affected by norms, values, behaviours and properties of the group and can affect the group with his own behaviour and traits.

The process of mutual interaction leads us to the concept of dynamics.

Group dynamics are defined as the social process of little groups having face to face interactions. The word dynamics comes from a Greek word that means force (strength); therefore group dynamics mean examining the forces that exist within groups. To give a frank definition, concept of group dynamics; states the affects and reactions in group members and the structure of the group by changes that arise at any part of the group (Davis, 1988).

\section{The Normative Effects of Group on an Individual}

When we consider the inner structure of a group, we know there are positional differences within members in all groups. Within group hierarchy, Is there a difference between members according to adaptation to group norms, or which members are more adaptive to group norms compared to others?

The most "adaptive behaviour" amongst three statuses (lower, middle and top) that is created in a group is seen amongst the middle ones who believe them to be partially accepted by the group.

For lowest status members, because they know that they are not favoured by the group, group lost its charm to an extent and generally they show less adaptive behaviour compared to the middle group.

Adaptive behaviour shown by the top statuses appears to be less compared to the middle ones. Because leaders who are accepted and beloved are feeling more secure; means they won as much status as they could earn. In respect to this, they feel more comfortable compared to the middle ones.

\section{The Effect of the Group to Individual Attitude Change}

Groups can increase or prevent attitude shifts, namely; if this attitude change is in the same direction with group norms, group acts as an augmenting factor to make this happen; if this attitude change collides with the group norm, group prohibits this attitude shift.

\section{Effect of a group on an Individuals Efficiency}

In analysis's done on groups, an individual is encouraged to do more in a group compared to what he does on his own. This phenomenon is defined as "social acceleration".

It is very interesting to see similar results on some research done on animals. For example, ants that excavate sand do it faster in groups of two or three compared to working alone. All these studies and their similarities have a common finding, which is that an individual does more work in a group compared to doing it alone. This competition within a group, the feeling of being evaluated by other group members and the effect of these feelings cause "Social Acceleration."

\section{Interpersonal Attraction and Repulsion in Groups}

Socio-metric observations regarding the fact that, an individual with a sympathetic and charming air gets the most attention amongst group members; shows that these individuals can change and affect the group structure and direct their colleagues and their environment. 
By doing so, a group can reorganize under the leadership of an outstanding and charming individual. The reason for this is that, individuals prefer to cooperate with charming individuals who can share same feelings and views with them.

Groups can have individuals with certain properties but also at the same time, they can also have individuals who are repulsive and quarrelsome. Such individuals usually remain alone in the group and only communicate with other individuals when it's necessary.

\section{Conclusions}

Formal structure comes forward when it comes to examining an organization structure and its properties; correspondingly, comes the conclusion that an organization is usually characterized as a formal structure without showing proper attention to human aspects. While it's necessary and mandatory for an organization to lean towards a formal structure, the fact that humane relations may also cause complicated issues should also not be ignored. Before everything else, success of a business depends on the ability and desire to do the job of the individuals who represent it. Because now it is proven that there is a system of sentiments in businesses. For this reason, there are great benefits to determining the role of humane factors within a structure and arranging the organization with respect to this. By doing so, new organization structure will evaluate reasoning, discovery and renovation of a member, strengthening their will to cooperate.

Modern organization thinkers, while they are organizing individuals, they benefit from group understanding on a vast scale. Groups are keystones of an organization structure and they are valid in every level of hierarchy chain. If distributing problems between top levels and chiefdom and then between chiefdom and employees will act as an effective tool to merging goals of the business and the group and will find solutions to some problems easier, chef or a higher status person needs to be a part of a work group made with groups below and above (Ülgen, -)

Table 4: Organization Structure and Groups

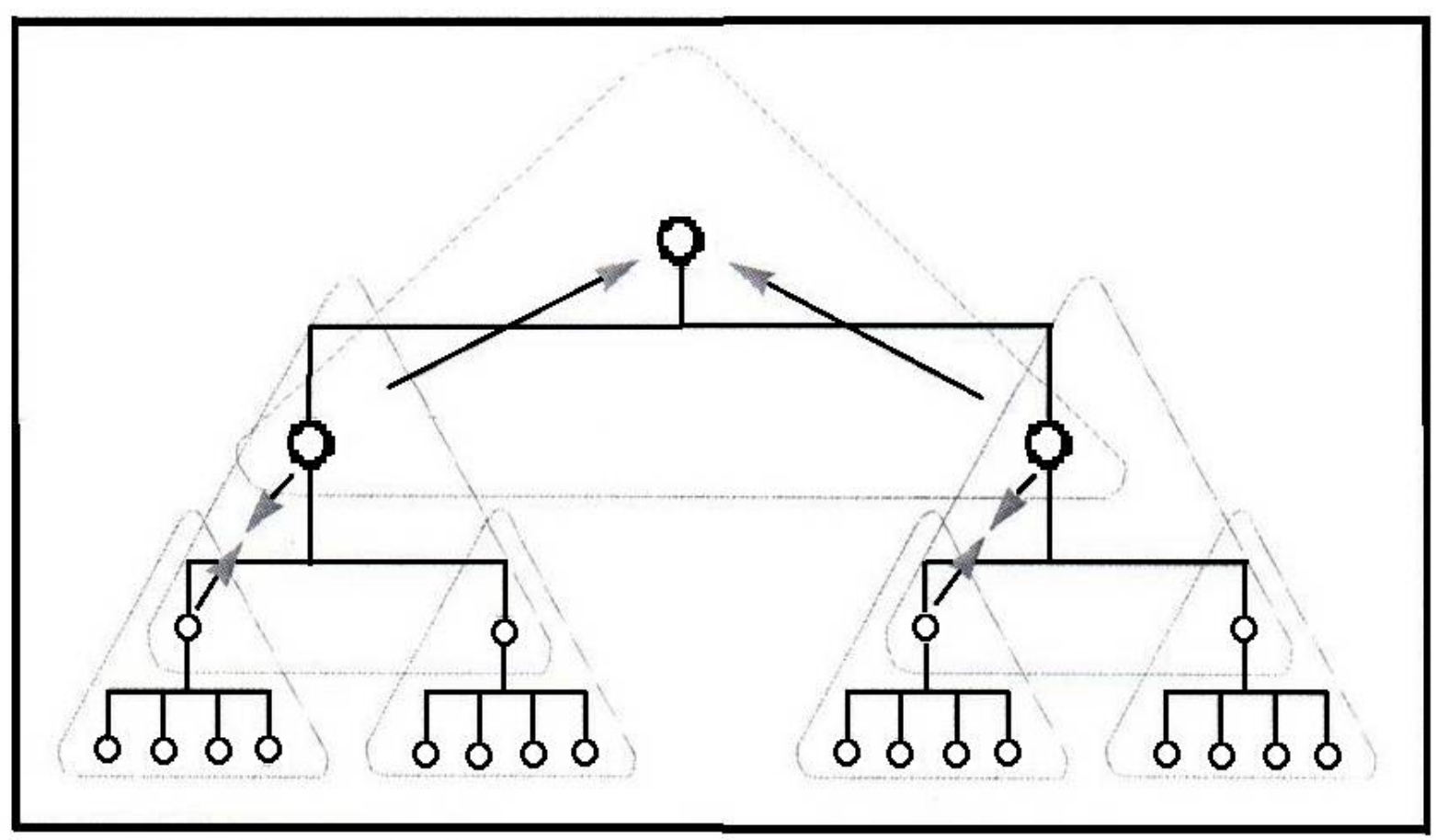

By doing so, an organization structure that makes it possible for little but connected groups to form will be founded (Likert, 1959).

These keystones that are based on groups need to make three functions real. 
Functions of managers who have the roles of being the hinge and the connector (Supplementary and Integrative); is to creature a group, keep that group as a whole and cohere with a higher group. In this state, first the responsible manager in this level needs to make this groups existence real, namely create the group. Secondly the manager will keep the group as a whole. However, while doing these, he also should not ruin his relations with his lower connected group. On the other hand, the fact that this manager comes from a higher group to a lower group accepting and embracing being a common opposition will also make the movement of the lower group more difficult. For example, saying "I know this to be a funny thing, but this is something we have to do according to higher ups" will intervene with the way organization works from start. For this reason, managers who are at the keystones of the organization should improve their technical, social and humane aspects beforehand. Furthermore, these managers need to know what kind of behaviours they need to show in order to make the goal real and increase the morale. This manager that acts as a connector between two levels carries information from lower group, which he is in harmony with, to a higher group, where he belongs to. Responsible individual of the lower group participates in defining the goals, preparing activity plans and various pressures on individuals. As a member of the higher group, works to make these goals and activities come real. On this level, he joins in defining the goals.

It depends on behaviours of the connectors who are between these two groups for such an organization to process better. Again with these connectors, it can be assumed that lower groups also have an effect on the decisions of the higher group.

\section{References}

Davis, K. (1998). İşletmede İnsan Davranışı. İstanbul: Yön Ajans.

Dereli, T. (1976). Organizasyonlarda Davranış. İstanbul: Fakülteler Matbaası.

Eren, E. (1984). Yönetim Psikolojisi. İstanbul: İ.Ü. İşletme İktisadı Enstitüsü Yayınları.

Kağıtçıbaşı, Ç, \& Cemalciler, Z. (2015). Dünden Bugüne Insan ve Insanlar Sosyal Psikolojiye Giriş. İstanbul: Evrim Yayınevi.

Likert, R. (1959). A Motivational Approach to a Modified Theory of Organization and Management (M. Haire, Ed.). Oxford: Modern Organization Theory.

Özalp, İ. (1986). İşletmelerde Yönetim Fonksiyonlar ve Organizasyon. Eskişehir: Bayteş Yayınları.

Ülgen, H. (1990). Işsletmelerde Organizasyon Illkeleri ve Uygulaması. İstanbul: Gençlik Basımevi.

Ülgen, H. (n.d.). Organizasyonlarda Beşeri Unsurun Önemi. i.Ü. İşletme Fakültesi Dergisi, 3. 190.

Ülgener, S. (1981). İktisadi Çözülmenin Ahlak ve Zihniyet Dünyası. İstanbul: Der Yayınları. 